\title{
Immune monitoring in patients with colorectal cancer stage II
}

\author{
Eva Zavadova ${ }^{1 *}$, Michal Vocka' ${ }^{1}$ Jan Spacek', Nicole Francis ${ }^{2}$, Bohuslav Konopasek', Terezie Fucikova ${ }^{3}$, \\ Helena Skalova ${ }^{4}$, Pavel Dundr ${ }^{4}$, Lubos Petruzelka', Tilman T Rau ${ }^{5}$, Carol Geppert ${ }^{5}$, Arndt Hartmann ${ }^{5}$ \\ From 30th Annual Meeting and Associated Programs of the Society for Immunotherapy of Cancer (SITC 2015) \\ National Harbor, MD, USA. 4-8 November 2015
}

Immunoscore has been shown to be a very powerful prognositc indicator in patients with clinically localized colorectal cancer, with no detectable tumour spread to lymph nodes or distant organs. These patients are usually treated with surgical removal of the tumour only. However, approximately $25 \%$ of these patients will have recurrence of their disease. No tumour-associated marker to predict the recurrence of this subgroup of patients and define who could benefit from adjuvant therapy is used in clinical routine[1] In addition to immunoscore, other parameters of the immune response are investigated - mostly cellular immunity and the production of immunosuppressive and neoangiogenic markers. Vascular endothelial growth factor (VEGF) is the factor responsible for neoangiogenesis and it is being considered as a possible prognostic marker of disease progression. Transforming growth factor-beta (TGFbeta) is also neoangiogenic and a highly immunosuppressive factor as it suppresses the body's natural immunity against tumours and is also being considered as another possible prognostic marker of disease progression.

\section{Aim}

To monitor the immune response in patients with stage II colorectal cancer, with a focus on cellular as well as humoral immunity. TGF-beta and VEGF levels were followed.

\section{Methods}

38 patients with stage II colon cancer included in the research project received routine cancer treatment. . Basic parameters - histological type and grade,

'Department of Oncology, General Teaching Hospital and 1st Faculty of Medicine Charles University, Prague, Czech Republic

Full list of author information is available at the end of the article proliferative markers - were established at baseline. Patients were evaluated by a clinical immunooncologist to exclude any immune disorders of allergic or autoimmune origin. TGF-beta and VEGF were measured using ELISA, and anti-tumour cellular immunity (CD4, CD8, T-reg, B cells) were measured via flow cytometry.

\section{Results}

In patients with stage II colorectal cancer, predominantly a depression in cellular immunity was seen. Plasma levels of immunglobulins were also reduced, particularly the IgG3 subtype. Most patients showed some clinical symptoms of immunodeficiency, such as frequent respiratory tract infections and/or herpetic infections. TGF-beta and VEGF plasma levels were increased.

\section{Conclusion}

The correlation of these neoangiogenic and immunosuppressive factors, as well as the state of anticancer immunity, could help in the future as a prognostic marker and contribute to the selection of targeted adjuvant as well as immune therapy in patients with colorectal cancer stage II.

\section{Dedication}

This project was supported by grant of Czech Ministery of Health, 15-28188A, League against cancer and PRVOUK.

\footnotetext{
Authors' details

${ }^{1}$ Department of Oncology, General Teaching Hospital and 1st Faculty of Medicine Charles University, Prague, Czech Republic. ${ }^{2} 1$ st Faculty of Medicine Charles University, Prague, Czech Republic. ${ }^{3}$ Institute of immunology and microbiology, General Teaching Hospital and 1st Faculty of Medicine Charles University, Prague, Czech Republic. ${ }^{4}$ Dept. of pathology, General Teaching Hospital and 1st Faculty of Medicine Charles University, Prague, Czech
} 
Republic. ${ }^{5}$ Institute of Pathology, University Erlangen-Nürnberg, Erlangen, Germany.

Published: 4 November 2015

\section{Reference}

1. Galon J, et al: Towards the introduction of the 'Immunoscore' in the classification of malignant tumours. Journal of Pathology 2014, 232(2):199-209.

doi:10.1186/2051-1426-3-S2-P266

Cite this article as: Zavadova et al:: Immune monitoring in patients with colorectal cancer stage II. Journal for ImmunoTherapy of Cancer 20153

(Suppl 2):P266.

Submit your next manuscript to BioMed Central and take full advantage of:

- Convenient online submission

- Thorough peer review

- No space constraints or color figure charges

- Immediate publication on acceptance

- Inclusion in PubMed, CAS, Scopus and Google Scholar

- Research which is freely available for redistribution

Submit your manuscript at www.biomedcentral.com/submit
() Biomed Central 